\title{
The Course Construction of "Fundamentals of Electric Motor and Drive" Under the Outstanding Engineer Education Training Plan
}

\author{
Shaoquan Zhang \\ Control Engineering College in Chengdu University of Information Technology, Chengdu, China \\ email:sqzhang@cuit.edu.cn
}

\begin{abstract}
Keywords: course construction; teaching method; teaching device; project teaching; information construction; assessment method

Abstract. This paper introduces the course construction in order to cultivate the students' engineering ideal and the practical ability. Teachers adjust teaching methods and teaching devices according to the students' feedback information. The project teaching of DC motor help students to understand the engineering application, and this content of stepper motor break the barriers between the courses. The course information construction is constantly improving.
\end{abstract}

\section{Introduction}

The outstanding engineer education training plan is a major reform program of Higher Education in China. In order to improve the quality of engineering personnel training, creating a number of engineering and technical personnel with innovative ability, adapt to the needs of economic and social development[1][2]. Electrical engineering and automation of our university is an experimental major in Sichuan Province. "Fundamentals of Electric Motor and Drive" as a core required course, according to the position and function of this course in the talent training program, constructed in syllabus, teaching content, teaching method, information technology and so on.

\section{Course Orientation and Teaching Content Adjustment}

This is an important professional course of Electrical Engineering and Automation which offered after basic courses. This course helps students to understand the basic theory and analysis methods of Electric Motor and Drive thoroughly, as well as to grasp the analysis methods to engineering practical problems.

Since the major establishment of electrical engineering and automation, this course has been a very important required course which named "Motor and Drive". With the $\mathrm{CDIO}$ (Conceive-Design-Implement-Operate) reform and the outstanding engineer education training plan, the course has been changed to "Motor Theory" and then" Fundamentals of Electric Motor and Drive ". During this period, the curriculum group actively carried out the teaching reform, and continuously enriched syllabus and teaching content.

\section{Combine Teaching Methods and Teaching Devices Flexibly}

This course is the one which has a strong project practice. Both circuit knowledge and magnetic circuit knowledge are needed, but also requires students to analysis and calculate on the basis of motor structure understanding. In order to obtain better teaching effect, a variety of teaching methods and teaching devices should be flexible combined according to the students' feedback information.

\section{Teaching Method}

Frequently used teaching methods in this course include lecture method, discussion method and project teaching method. The traditional lecture method and discussion method runs through the whole teaching process. The lecture method is often used at introduction part such as motor structure, working principle, formula derivation and so on. In the process, teacher will set up a few questions to discuss so that students can understand and master better. In view of the practice of this course, different engineering projects will be showed after every basic theory of the DC motor, transformer, 
induction motor and synchronous motor. Students have a strong interest in the project teaching which has a full project life cycle, the discussion method and induction method will be used frequently.

The previous teaching experience has proved that a variety of teaching methods can effectively mobilize the enthusiasm of the students, and promote students to actively think. At the same time, it also strengthens the teachers' acquaintance of students' learning effect.

\section{Teaching Device}

Frequently used teaching devices in this course include writing on the blackboard, multimedia teaching platform and Flash animation. Part of formulas derivation are written on the blackboard, then teacher can flexible control the schedule according to the students' understanding degree. Most of the content will be showed by the multimedia teaching platform. By this teaching device, teacher will focus on "lecture" instead of "writing" to increase the amount of classroom information. For the structure and working principle of the motor, three-dimensional space can't be showed fully by the cross section and the longitudinal section except Flash animation. A variety of teaching devices enrich the form of teaching, improve students' learning interest and understanding ability, so as to improve the teaching efficiency, promote the teaching level, and improve the teaching quality.

\section{Engineering Practice}

The core of engineering education is practical ability and innovative ability. The engineering practice of this course includes the experiment and project teaching. Three experiments are carried out in professional laboratory which need 8 class hours. Project teaching is inserted in the theory teaching.

\section{Experiment Teaching}

The arrangement of the experiment is divided into three parts: the experiment preview, the experiment operation and the experiment report. Before entering the laboratory, the students are required to preview to understand the purpose of the experiment and the basic theory of the experiment. During the experiment, the students are required to be familiar with the experimental operation platform, and keep in mind the operation safety precautions. Teacher must pay attention to training students' some important quality such as the team spirit, the ability of group cooperation, and the practical ability. Students are required to take on different roles in the experimental group, such as operator, observer and recorder, and work together to complete the whole experimental task. At the same time, students and teacher are required to eliminate the possibility of experimental failure according to different phenomena. After the experiment, students must analyze the experimental phenomenon and the experimental results, and then write the experiment report.

\section{Project Teaching}

The project teaching of DC motor and stepper motor are showed as the example in the following paper.

The DC motor is the first kind of electric motor introduced in this course. After the theoretical knowledge of structure and armature winding, the wingding coiling and the wingding dipping technique in factory are showed by Flash. So that students can know more about the production process and technology of motor. After the theoretical knowledge of DC motor electric drive, the electric toys are showed to demonstrate the engineering application of the motor control. After the end of all theoretical knowledge of DC motor, students should finish the last part which names "application of DC motor in electric railway". This part is not entirely displayed by teacher, and students must be actively involved in it. At first students need to access information to understand different DC motors used in different development stages of electric locomotive, and then to understand the control methods of the current DC traction motor. At last, the whole class should discuss the project together with teacher.

The stepper motor is the last kind of electric motor introduced in this course. The students understand the working principle of stepper motor more easy than others in front, and then Numerical Control machine was showed as the end of project teaching. The use of NC machine is the 
compulsory item of metalworking practice to students in the next summer vacation. The whole design process of controlling NC machine will be displayed in this project teaching. Firstly, it is necessary to control the pulse signal of the stepper motor, and how to control the pulse signal have showed in the prerequisite compulsory subject names Digital Circuit and Digital Logic Design. Then, the power matching of the pulse signal and the motor input signal should be analyzed. Power amplification is needed when the pulse signal output power is not enough to drive the stepper motor, which has showed in the prerequisite compulsory subject names Analog Electronic Technology. Finally, the output of the stepper motor should be analyzed. The closed-loop control is needed when the products of NC machine do not meet the requirements, which has showed in the prerequisite compulsory subject names Principles of Automatic Control. In the end of the project teaching, students will get the connection between the specialized course and the basic course, and the barriers between different courses in the true sense of breaking.

Visible from above, the main purpose of the project teaching of DC motor is engineering application, and the main purpose of stepper motor is to guide students understand the different courses are not isolated but closely. Other project teachings are different from above, but are carefully designed by teachers to focus on the goal of cultivating students' engineering vision and innovative ability.

\section{Information Construction}

Teachers has delivered some course materials by network storage such as teaching courseware, experimental instruction and homework. The number of visits was 9377 within several years, and which shows students' tremendous demand for information construction. However, there is no interaction between teachers and students in the basic function of network storage. Therefore, it is needed to construct the network teaching platform of information communication between teaching and learning. The new network teaching platform in addition some interactive modules for teaching and learning such as teaching calendar, answering questions (including curriculum discussion, common problems, automatic question and answer questions in E-mail), test library and test paper library. The information construction can make teaching methods more abundant, and it is more convenient for students to obtain learning resource.

\section{Assessment Method}

The traditional way of examination is the final exam by test paper, it is the end of the assessment methods. However, only through one examination, based on the students' test scores, it is difficult to comprehensively measure the quality of students' learning effect[3]. This course adopts the form of formative assessment step by step, comprehensive knowledge, ability and professionalism to carry out course evaluation.

The result of this course include two parts, daily achievement(30\%) and the final exam(70\%). Daily achievement include not only the traditional assessment contents such as attendance, homework and classroom practice, but also the teacher's evaluation such as engineering literacy, learning attitude and experimental ability. The final exam increases the contents of the experiment and engineering problems except the traditional theoretical exercises. Analyses of the outstanding problems in the assessment should be conducted as a basis for continuous improvement of this course. The constantly optimization of the curriculum assessment methods and assessment system is needed, so that the overall assessment of the teaching objectives to reflect the degree of realization. At the same time, it can stimulate students' learning enthusiasm and initiative.

\section{Conclusion}

This paper introduces the course construction and teaching practice of "Fundamentals of Electric Motor and Drive ". The purpose is to cultivate students' engineering ideal and practical ability. As a 
result, the students' learning enthusiasm and initiative were effectively improved, and favorable teaching effect was obtained.

\section{Acknowledgements}

This paper is the result of the excellent course construction project in Chengdu University of Information Technology. I want thank all the colleagues in the teaching and research team.

\section{References}

[1] L. Jian: The Development of General Standards for "A Plan for Educating and Training Outstanding Engineers", Research in Higher Education of Engineering, Vol. 4(2010), p. 21-29

[2] L. Jian: On Outstanding Engineers' Innovation Ability Training, Research in Higher Education of Engineering, Vol. 5(2012), p.1-17

[3] Z. Shaoquan, Design and Assessment Method for Project Level One, Value Engineering, Vol. 6(2011), p.22-23 